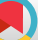

\title{
Construction and Validity and reliability of Survey of Marital Pathology Woman with Symptoms of Obsessive-Compulsive
}

\section{Personality}

\author{
Somaye Hashemi Mofrad, ${ }^{1}$ Rezvano Sadat Jazayeri, ${ }^{1,}{ }^{*}$ Maryam Fatehizade, ${ }^{1}$ Ozra Etemadi, ${ }^{1}$ and \\ Mohammadreza Abedi ${ }^{1}$ \\ ${ }^{1}$ Department of Counseling, Faculty of Education and Psychology, University of Isfahan, Isfahan, IR Iran \\ "Corresponding author: Rezvano Sadat Jazayeri, Department of Counseling, Faculty of Education and Psychology, University of Isfahan, Isfahan, IR Iran. Tel: +98-9131171463, \\ E-mail: r.jazayeri@edu.ui.ac.ir
}

Received 2017 October 10; Revised 2017 December 20; Accepted 2018 March 11

\begin{abstract}
Objectives: The purpose of this study was to construction and validity and reliability of a survey about marital pathology a couple of women had symptoms of obsessive-compulsive personality.

Methods: The method that was used for this survey was combination of exploratory research that was conducted in two steps. The first step was a qualitative factors discovery analysis one which included 15 semi-structured interviews with women with symptoms of obsessive-compulsive personality disorder and husbands, 14 semi-structured interviews with family experts and clinical psychologists and psychiatrists and review of scientific resources. Related articles were gathered based on qualitative content analysis. In the second phase, the validity and reliability of the data collection instrument were investigated. The statistical population consisted of all married women with obsessive-compulsive symptoms referring to counseling centers in Isfahan and their husbands. Results: The research sample consisted of 70 married women with obsessive-compulsive symptoms and their husbands (140 participants) who were selected via the purposive sampling technique. Factor analysis was conducted through the SPSS software program. The research findings indicated that the questionnaire has six factors including extreme perfectionism, extreme concern, algebraic and focused (non-participatory) control, extreme sensitivity to affairs, coldness and sexual dysfunction, inflexibility. The results of factor analysis revealed a significant percentage of variance of the study variable by factors. As a result, the Cronbach's alpha coefficient of the total test was obtained as 0.96 .

Conclusions: The scale enjoyed high levels of validity and reliability which contribute to obtaining factors and has the ability of identifying marital pathology of women with symptoms of obsessive-compulsive personality in clinical and couple researches.
\end{abstract}

Keywords: Reliability, Woman with Symptoms of Obsessive-Compulsive Personality, Marital Pathology, Validity

\section{Background}

Marriage is described as the most important principle and basis of human relations because it provides the basic structure of family relationships and nurture of the next generation (1). Different studies have indicated that married individuals have higher levels of psychological health and happiness (2). But appropriate relations cannot be easily accessible and conflicts are inevitable in all close relations (3). Marriage is not an exception; even it is somehow necessary for the continuous function of couple relationships. However, when these problems are not properly identified and appropriately managed, they may result in dissatisfaction and psychological problems including depression, anger, anxiety, and damages (4). Damage refers to a sickly condition preventing individuals' normal func- tions. Damages in a marital life refer to a set of factors causing marital conflicts, reduce the level of couples' satisfaction and compatibility, and hinder normal performances of a marital life (5). As a result, investigating grounds for occurrences of marital conflicts has a significant role in reducing couples' problems and decreasing the divorce rate in societies (6).

Of factors affecting the occurrence of damages in martial relationships is personality disorder. Research shows that personality characteristics are effective on satisfaction with marital relationships and compatibility between couples (7). Personality disorders are a set of psychological disorders whose main properties are strict and inflexible behaviors. Those behaviors damage individuals in that they prevent their compatibility with daily living requirements 
and disrupt their relationships with others (8). They affect personal performances including self-control, behavioral, cognitive, emotional, interpersonal, and biological processes (9). Studies indicate that the important problem common in all personality disorders is inability in making relations, especially close and friendly ones. Symptoms of those disorders are seriously related to martial conflicts (10). One of the personality disorders is Obsessive-compulsive personality disorder (OCPD).

Diagnostic and statistical manual of mental disorders for OCPD are as follows:

a. Significant defects in personality performance: personal and interpersonal performance

b. Disease personality traits in coercions and negative emotions

c. Defects in personality performance: it should be intact over time and different situations.

d. Defects in personality performance cannot be justified with the individual transformation stage and the social environment.

e. Defects in personality performance are not due to physiological effects of drug use or general medical conditions.

The prevalence of this disorder among patients with outpatient surgery is from $8 \%$ to $9 \%$ and for the general population is from $2 \%$ to $8 \%$. It is considered as an incompatible and chronic pattern of preoccupation with orderliness and details. It also requires control over the environment and individuals; as a result, it can result in damages to individuals' lives $(11,12)$ believe that individuals with this disorder have eight personality traits including perfectionism, rigidity, preoccupation with details, excessive devotion to work, over conscientiousness and inflexibility regarding morals and values, miserliness, hoarding, and inability to delegate tasks. Research has illustrated that behaviors such as miserliness and the inability to dispose of old-fashioned devices cause dissatisfaction in their lives $(13,14)$.

Intimate relationships, self-expression, diversity of feelings, and admiration of others are other factors affecting marital satisfaction which are lacking in individuals with OCPD (15). In addition, (16) found out that symptoms of OCPD in martial relationships affects them and result in reducing their quality of marital life. They also emphasized that OCPD is one of the most important factors affecting marital dissatisfaction. Therefore, considering the negative effects of this correlation on couple relationships and an increase of $17.5 \%$, in the divorce rate in the first quarter of 2017 in Iran (17), which is one of the important reasons for the incompatible personality characteristics of couples, careful evaluation these characteristics are necessary to contribute to reducing them via local tests that are fully in line with the characteristics of the Iranian context. Of course, there are questionnaires developed on the measurement of obsessive-compulsive disorder, the tridimensional personality questionnaire in obsessive-compulsive disorder (18) and the obsessive-compulsive personality disorder (19), but no questionnaire was found matching paired damages of the couples. Thus, the development and standardization of this test is of a theoretical and practical importance.

In terms of applicability, the present questionnaire can be applied in all counseling centers by therapists and contribute the identification of martial problems and consequently facilitation of the treatment process for enhancing quality of marital life and enrichment of marital relationships of those individuals. Therefore, the present study investigates the development of marital interpersonal damages of women with OCPD. In addition, the study is to answer this question whether the questionnaire enjoys appropriate validity and reliability?

\section{Methods}

Considering objectives, hypotheses, and nature of the study, the present study is an exploratory mixed-method study. The fundamental principle of the investigation with mixed-method is the use of qualitative and quantitative techniques in some stages of the research. In fact, qualitative and quantitative research methods can be simultaneously or sequentially conducted so that the general method has complementary strengths and nonoverlapping weaknesses (20). The first stage of the research was the analysis of the qualitative content. This method includes content analysis of qualitative data and their classification for understanding their meanings (21). The population of the study consisted of all married women with OCPD referring to counseling centers of Isfahan and their husbands in 2016.

\subsection{Sampling Method}

Sampling was conducted at the stage of developing the test according to the following stages:

The first sampling method: first of all, from among the domestic and foreign scientific sources and literature (including electronic sources, books, theses, and journals) related to OCPD and accessible for the researchers and published from 1980 to 2016, some resources were selected until saturation.

The second sampling method: 14 semi-structured interviews were conducted with experts of family counseling and psychiatrists and clinical psychologists. 
The third sampling method: in this stage, 15 semistructured interviews were conducted with women with OCPD and their husbands.

Those individuals were selected via the purposive sampling method. The purposive sampling method used for selecting those participants with the maximum information about the research questions (22).

Sampling was carried out in the standardization phase of the test in as follows:

The research sample consisted of 70 married women with obsessive-compulsive symptoms and their husbands (totally 140 participants) selected via the purposive sampling method from three counseling centers in Isfahan City. Three counseling centers were selected from among the counseling centers of Isfahan via the convenience sampling technique. Furthermore, participants aged from 25 to 40 years, their marriage duration ranged from 1 to 15 years, their education ranged from diploma to MA/MSc.

\subsection{Research Instrument}

1. ENRICH marital satisfaction scale: it is a 47item instrument for assessment of potential problematic grounds by identifying strengths and enrichment of marital relationships. This scale was developed by Olson, Fournier and Druckman in 1982. It is used also for identifying couples requiring counseling and reinforcing their relationships. Moreover, it has been used as a valid instrument in different studies for probing marital satisfaction. This scale consists of 9 sub-scales of marital relationship, personality issues, conflict resolution, financial management, leisure activities, sexual relationship, children and parenting, family and friends, and religious Orientation (23). The scale has been developed based on the five-point Likert scale as 1 . Strongly disagree, 2. disagree, 3. No idea, 4. agree, and 5. strongly agree. Participants must choose one of the options according to their agreement degrees. The option "no idea" is used for when participants do not know how to answer a certain question. Participants were asked to not use this option as much as possible. The minimum score of this scale is 47 and the maximum score is 235. Higher scores show higher couples' satisfaction with their marital relationship. Soleimanian (1994) developed this scale in Iran in short-from. Olson et al. (1989) reported reliability of the 47 -item scale as 0.92 via Cronbach's alpha. Soleimanian (1995) translated the Martial Satisfaction Scale and reported its internal consistency as 0.95 . The correlation coefficient of this questionnaire with the Family Satisfaction Scale ranges from 0.41 to 0.60, and its correlation coefficient with the Satisfaction with life scale ranges 0.32 to 0.41 . It shows its acceptable construct validity. All subscales of the ENRICH Marital Satisfaction Scale separate satisfied couples for unsatisfied ones. This issue indicates that this scale has appropriate criterion validity. Furthermore, its reliability was obtained as 0.95 via the Cronbach's alpha method (23). Validity of the scale was obtained as 0.93 for men and 0.94 for women, and 0.94 for both groups using Pearson correlation coefficient and testretest method within a week's interval (24).

2. Marital conflict questionnaire: it is a 42-item instrument developed by Barati and Sanaei (1996) for assessing couples' conflicts. It assesses 7 dimensions of marital conflicts as follows: 1 ) reduction in collaboration 2) increase in emotional reactions 3 ) increase in gaining supports from the children 4) increase in personal relationships with relatives 5) reduction in family relationships with the spouse' relatives and friends 6 ) reduction in sexual relationship and 7) separation of financial affairs from each other. Five options of always (5), mostly (4), sometimes (3), rarely (2), and never (1) were considered for each item. The maximum score is 201 and the minimum score is 42 . Its reliability coefficient was obtained as 0.53 for the whole scale via Cronbach's alpha coefficient. In addition, reliability of the seven subscales are as follows: 1 ) reduction in collaboration as 0.3 , increase in emotional reactions as 0.73 , the increase in gaining supports from the children as 0.60 , increase in personal relationships with relatives as 0.64 , reduction in family relationships with the spouse' relatives and friends as 0.64 , reduction in sexual relationship as 0.5 , and separation of financial affairs from each other as 0.51 . The scale also enjoys acceptable content validity (23).

\subsection{Procedure}

With regard to the qualitative research method used in the present study, the researchers collected data for several times to reach data saturation. Thus the sample size was not predefined and data saturation determined the sample size. The data were collected from 14 semi-structured interviews with experts, 15 semi-structured interviews with women with OCPD and their husbands, and scientific resources. The number of interviews can be changed considering the multiple resources of the data including books and articles documents, and researchers' personal notes (25). The participants were selected according to the diversity of the data until reaching data saturation. Data saturation means that no new concept will appear and all conceptual levels are completed; as a result, researchers conclude that they have reached the same data in previous stages (26). For doing semi-structured interviews, individuals with inclusion criteria were selected via the purposive sampling method and diagnosis tests appropriate for showing personality and identifying demographic characteristics and their main reasons for referring to counseling centers (including desire to divorce, marital dissatisfaction and extra-marital relationships) were adminis- 
tered until reaching data saturation. 29 interviews were conducted on 14 experts (psychiatrists and psychotherapists) and 15 women with OCPD and their husbands. After a brief explanation and clarification of reasons for conducing the research as well as the aim of using the voicerecorder and assuring them of confidentiality, interviews were conducted with their consents. The duration of interviews were dependent on conditions and ranged from 30 to 70 minutes. Each interview included some general questions such as "how is your marital life?" those questions were as the primary framework for entering the interview; during the interviews, more questions were asked. Interview guide questions were differently asked with regard to different interviewees about the same domains of martial life. Other questions related to relationships with husbands, children, and others were also asked. Meaning units were prepared out of interviews and then analysis units were severally revised, coded in terms of conceptual and meaning similarities, and then categorized. Data analysis was conducted via the qualitative content analysis technique and contractual approach (27).

Finally, the data were categorized into five categories including growth damage, interpersonal damages, damages of relationships with husbands, damages of relationships with children, and damages of relationships with others. The new data were compared with all data in order that the desirable orientation between data appear. In the second stage, to prepare a questionnaire for assessing marital damages of women with OCPD based on the mentioned five categories, 110 questions (items) were developed. To validate the questionnaire, notes, interviews, analyzed categories, extracted primary codes, and developed questions were submitted to several family specialists, clinical psychologist, and psychiatrists and their ideas and comments were collected. Then, recommended amendments were done. The new data were compared with all data in order that the desirable orientation between data appear. Finally, the categories extracted from qualitative interviews were confirmed by the experts. Allocation of sufficient time to the research as well as open and sympathetic communication with interviewees were among other factors increasing the validity of data (28). Consequently, some questions were submitted to five experts for assessing content validity. The aim of experts' investigations was to be sure of matching the questionnaire's questions with the extracted categories. After revising and deleting propositions and sentences not agreed by two of the experts, the primary questionnaire with 100 items was prepared and conducted on 70 couples (140 participants) including women with OCPD and their husbands. Items were regulated in the five-point Likert scale (ranging from 5 as "very much" to 1 as "very little").

\subsection{Data Analysis}

Following the collection of the data, they were analyzed via exploratory factor analysis and using SPSS software. In addition, to analyze the data, conventional testing methods including validation, factor analysis and calculation of reliability coefficients were used. To determine the validity of questionnaire, three methods of content validity, factor analysis, and convergent/divergent validity were used for the marital conflicts scale and ENRICH Marital Satisfaction Scale. To probe content validity, all questions whose relatedness was not confirmed by two experts were deleted. Finally, the final 100-item questionnaire was analyzed with the factor analysis technique. In addition the content validity coefficient was obtained as 0.9. It indicates that the questionnaire has an appropriate content analysis. To calculate construct validity of the questionnaire conducted on 70 couples (including women with OCPD and their husbands), exploratory factor analysis was employed.

\section{Results}

To measure sampling adequacy for each variable in the model and for the complete model Kaiser-Meyer-Olkin (KMO) Test was employed. Findings indicate that the sample size is adequate because the KMO value is obtained as 0.902 which is close to 1 . In addition, Brtlett's sphericity test was used to determine whether the correlation matrix has significant difference with zero correlation and consequently doing factor analysis is justified. Bartlett's test statistic was obtained as 1176.297 at the significance level 0.001 .

To investigate this issue that the study measurement instrument is saturated with several factors, three main indices were considered: 1 . eigenvalue, 2 . the variance ratio explained by each factor, and 3. the rotated graph of eigenvalues or Scree Plot.

Primary statistical characteristics obtained from analyzing main categories are represented in Table 1 . This table shows that eigenvalues of 22 factors are bigger than 1 , and the variance coverage common among variables for these 22 factors was obtained as $92.29 \%$. However, these 22 factors overlapped for many questions. This set of factors could not present fully distinct factors. Thus main factors in the range from 5 to 8 factors were analyzed in order that the best model can be obtained. The results indicated that extraction of 6 factors explained 58.61\% of the variance. In addition, radical perfectionism with eigenvalue as 19.55 explained $19.55 \%$, radical anxiety with eigenvalue as 10.82 explained $10.82 \%$, coercive and focused (nonparticipatory) control with eigenvalue as 7.64 explained 
$7.64 \%$, radical sensitivity to affairs with eigenvalue as 7.54 explained $7.54 \%$, frigidity and lack of sexual enjoyment with eigenvalue as 7.12 explained $7.12 \%$, and inflexibility with eigenvalue as 5.93 explained $5.93 \%$ of the total variance.

Table 1. Primary Statistical Characteristics of the 22-Factor Questionnaire with the PC Method

\begin{tabular}{|c|c|c|c|}
\hline Factor & Eigenvalue & Variance Percentage & Percentile \\
\hline $\mathbf{1}$ & 26.91 & 26.91 & 26.91 \\
\hline 2 & 11.51 & 11.51 & 38.43 \\
\hline 3 & 6.46 & 6.46 & 44.90 \\
\hline 4 & 5.02 & 5.02 & 49.93 \\
\hline 5 & 4.63 & 4.63 & 54.56 \\
\hline 6 & 4.05 & 4.05 & 58.61 \\
\hline 7 & 3.69 & 3.69 & 62.31 \\
\hline 8 & 3.38 & 3.38 & 65.69 \\
\hline 9 & 2.94 & 2.94 & 68.64 \\
\hline 10 & 2.75 & 2.75 & 71.40 \\
\hline 11 & 2.67 & 2.67 & 74.07 \\
\hline 12 & 2.45 & 2.45 & 76.53 \\
\hline 13 & 2.16 & 2.16 & 78.70 \\
\hline 14 & 1.98 & 1.98 & 80.68 \\
\hline 15 & 1.89 & 1.89 & 82.58 \\
\hline 16 & 1.74 & 1.74 & 84.32 \\
\hline 17 & 1.55 & 1.55 & 85.88 \\
\hline 18 & 1.48 & 1.48 & 87.36 \\
\hline 19 & 1.35 & 1.35 & 88.72 \\
\hline 20 & 1.26 & 1.26 & 89.99 \\
\hline 21 & 1.18 & 1.18 & 91.18 \\
\hline 22 & 1.11 & 1.11 & 92.29 \\
\hline
\end{tabular}

The contribution of factor one in the variance of all variables is significant and is fully distinct of the contribution of other factors. In addition, from factor, the chart slope is crossed and roughly smooth. After extracting 6 factors, statistical characteristics of the questionnaire were re-estimated (Table 2), and the minimum eigenvalue was obtained as 5.93. This value was not significantly compatible with the suggested criterion. Factors 1 to 6 explained $19.55,10.82,7.64,7.54,7.12$, and $5.93 \%$ of the variance of variables respectively. They also totally explained $58.61 \%$ of total variance of the variables. The contribution of radical perfectionism was significant. The results of calculating the contribution degree of each question indicated that the lowest contribution degree was as 0.33 for question 89 , while the highest contribution degree was as 0.87 for question 11. In addition, the contribution degrees of most questions were bigger than 0.3.

Table 2. Statistical Characteristics of the Primary 6-Factor Questionnaire Obtained Via the PC Method

\begin{tabular}{lccc}
\hline Factor & Eigenvalue & $\begin{array}{c}\text { Variance } \\
\text { Percentage }\end{array}$ & Percentile \\
\hline $\begin{array}{l}\text { Radical } \\
\text { perfectionism }\end{array}$ & 19.55 & 19.55 & 19.55 \\
\hline Radical anxiety & 10.82 & 10.82 & 30.37 \\
\hline $\begin{array}{l}\text { Coercive and } \\
\text { focused (non- } \\
\text { participatory) } \\
\text { control }\end{array}$ & 7.64 & 7.64 & 38.01 \\
\hline $\begin{array}{l}\text { Radical sensitivity } \\
\text { to affairs }\end{array}$ & 7.54 & & 45.55 \\
\hline $\begin{array}{l}\text { Frigidity and lack } \\
\text { of sexual } \\
\text { enjoyment }\end{array}$ & 7.12 & 7.54 & 52.67 \\
\hline \begin{tabular}{l} 
Inflexibility \\
\hline
\end{tabular} & 5.93 & 7.12 & 58.61 \\
\hline
\end{tabular}

As indicted in Table 3, questions relate to each factor are identified. Naming the six factors were investigated and determined considering the contents of questions and the experts' ideas.

There is a significant correlation between radical perfectionism and radical anxiety with the correlation coefficient ass 0.73. In addition, Cronbach's alpha coefficient for radical perfectionism was obtained as 0.90 and that of radical anxiety was obtained as 0.74 . A) Calculating internal consistency of factors of Marital Problems Scale of women with OCPD (calculation of the Cronbach's alpha coefficient) (Tables 4 and 5)

As indicated in the results of analysis of Pearson correlation, there significant correlations among the six factors. Therefore, it can be concluded that this questionnaire has acceptable validity. To investigate convergent/divergent validity of the mentioned questionnaire, the two marital conflicts scale and ENRICH Marital Satisfaction Scale were employed. The results indicated that there is a positive correlation between the researcher-made questionnaire with the marital confect scale (0.74) and negative correlation with the ENRICH: marital satisfaction scale (EMS) (0.74 ), both of which are significant at 0.001 . The existence of a significant correlation between the researcher-made questionnaire and the other two questionnaires confirms convergent/divergent validity of the mentioned questionnaire. 
Table 3. Sentences Indicating the Construction of Main Factors of the Questionnaire and Their Factor Coefficients

\begin{tabular}{|c|c|c|c|c|c|c|c|c|c|c|c|c|c|}
\hline $\begin{array}{l}\text { Frigidity } \\
\text { and Lack } \\
\text { of Sexual } \\
\text { Enjoy- } \\
\text { ment }\end{array}$ & $\begin{array}{l}\text { Factor Co- } \\
\text { efficients }\end{array}$ & $\begin{array}{c}\text { Radical } \\
\text { Sensitiv- } \\
\text { ity to } \\
\text { Affairs } \\
(12)\end{array}$ & $\begin{array}{l}\text { Factor Co- } \\
\text { efficients }\end{array}$ & $\begin{array}{l}\text { Inflexibility } \\
\text { (13) }\end{array}$ & $\begin{array}{l}\text { Factor Co- } \\
\text { efficients }\end{array}$ & $\begin{array}{c}\text { Coercive } \\
\text { and } \\
\text { Focused } \\
\text { Control } \\
(13)\end{array}$ & $\begin{array}{l}\text { Factor Co- } \\
\text { efficients }\end{array}$ & $\begin{array}{c}\text { Radical } \\
\text { Anxiety } \\
(16)\end{array}$ & $\begin{array}{l}\text { Factor Co- } \\
\text { efficients }\end{array}$ & $\begin{array}{l}\text { Radical } \\
\text { Perfec- } \\
\text { tionism }\end{array}$ & $\begin{array}{l}\text { Factor Co- } \\
\text { efficients }\end{array}$ & $\begin{array}{c}\text { Radical } \\
\text { Perfec- } \\
\text { tionism } \\
(29)\end{array}$ & $\begin{array}{l}\text { Factor Co- } \\
\text { efficients }\end{array}$ \\
\hline Q31 & 0.707 & Q41 & 0.777 & Q83 & 0.585 & Q60 & 0.686 & Q11 & 0.870 & Q21 & 0.629 & Q87 & 0.863 \\
\hline Q30 & 0.688 & Q 84 & 0.698 & Q76 & 0.574 & Q93 & 0.589 & Q6 & 0.870 & Q2 & 0.627 & Q53 & 0.792 \\
\hline Q28 & 0.672 & Q38 & 0.692 & Q74 & 0.563 & Q67 & 0.565 & Q4 & 0.831 & Q56 & 0.623 & Q69 & 0.782 \\
\hline Q34 & 0.641 & Q 42 & 0.643 & Q12 & -0.548 & Q65 & 0.560 & Q18 & 0.730 & Q20 & 0.621 & Q15 & 0.764 \\
\hline Q33 & 0.627 & Q39 & 0.566 & Q75 & 0.541 & Q71 & 0.548 & Q13 & 0.719 & Q14 & 0.614 & Q3 & 0.762 \\
\hline Q32 & 0.614 & Q35 & 0.552 & Q36 & 0.531 & Q62 & 0.528 & Q1 & 0.693 & Q23 & 0.607 & Q51 & 0.754 \\
\hline Q100 & 0.588 & Q25 & 0.493 & Q78 & 0.493 & Q91 & 0.527 & Q79 & 0.681 & Q19 & 0.604 & Q9 & 0.748 \\
\hline Q44 & 0.422 & Q5 & 0.482 & Q77 & 0.482 & Q81 & 0.499 & Q96 & 0.666 & Q22 & 0.584 & Q27 & 0.741 \\
\hline \multirow[t]{11}{*}{ Q45 } & 0.384 & Q55 & 0.482 & Q98 & -0.476 & Q72 & 0.495 & Q37 & 0.648 & Q57 & 0.582 & Q10 & 0.713 \\
\hline & & Q24 & 0.416 & Q73 & -0.479 & Q63 & 0.466 & Q8 & 0.634 & Q52 & 0.577 & Q29 & 0.711 \\
\hline & & Q50 & 0.372 & Q99 & -0.429 & Q68 & 0.395 & Q85 & 0.621 & Q 61 & 0.574 & Q16 & 0.700 \\
\hline & & Q49 & 0.372 & Q90 & 0.423 & Q82 & 0.386 & Q97 & 0.616 & Q66 & 0.560 & Q80 & 0.696 \\
\hline & & & & Q 64 & 0.413 & Q46 & -0.363 & Q48 & 0.577 & Q95 & 0.544 & Q94 & 0.689 \\
\hline & & & & & & & & Q17 & 0.549 & Q70 & 0.516 & Q92 & 0.682 \\
\hline & & & & & & & & Q86 & 0.535 & Q59 & 0.505 & Q58 & 0.669 \\
\hline & & & & & & & & Q7 & 0.511 & Q 43 & -0.406 & Q40 & 0.662 \\
\hline & & & & & & & & & & Q 54 & 0.385 & Q26 & 0.660 \\
\hline & & & & & & & & & & Q 89 & 0.330 & Q47 & 0.651 \\
\hline & & & & & & & & & & & & Q88 & 0.648 \\
\hline
\end{tabular}

Table 4. Cronbach's Alpha, Guttman, and the Spearman-Brown Coefficients of the Factors of Questionnaires

\begin{tabular}{lccc}
\hline $\begin{array}{l}\text { Statistical } \\
\text { Indices }\end{array}$ & $\begin{array}{c}\text { Alpha } \\
\text { Coefficient }\end{array}$ & $\begin{array}{c}\text { Guttman } \\
\text { Coefficient }\end{array}$ & $\begin{array}{c}\text { Spearman- } \\
\text { Brown } \\
\text { Coefficients }\end{array}$ \\
\hline $\begin{array}{l}\text { Radical } \\
\text { perfectionism }\end{array}$ & 0.96 & 0.94 & 0.95 \\
\hline $\begin{array}{l}\text { Radical } \\
\text { anxiety }\end{array}$ & 0.94 & 0.88 & 0.91 \\
\hline $\begin{array}{l}\text { Coercive and } \\
\text { focused } \\
\text { control }\end{array}$ & 0.82 & 0.75 & 0.78 \\
\hline $\begin{array}{l}\text { Radical } \\
\text { sensitivity to } \\
\text { affairs }\end{array}$ & 0.88 & 0.80 & 0.86 \\
\hline $\begin{array}{l}\text { Frigidity and } \\
\text { lack of sexual } \\
\text { enjoyment }\end{array}$ & 0.87 & 0.77 & 0.86 \\
\hline \begin{tabular}{l} 
Inflexibility \\
\hline
\end{tabular} & 0.76 & 0.67 & 0.65 \\
\hline
\end{tabular}

\section{Discussion and Conclusions}

The present study was conducted with the aim of development and validation of a researcher-made questionnaire for assessing marital damages of women with OCPD. The data were analyzed via exploratory factor analysis and with the conventional testing techniques including validity, factor analysis, and calculation of reliability coefficients. To determine validity, three methods of content va- lidity, factor analysis (30), and convergent/divergent validity of the marital conflicts scale and ENRICH Marital Satisfaction Scale were used (23). To investigate content validity of all questions whose relatedness was not confirmed by the two experts, were deleted. As a result, the final form of the questionnaire with 100 items were analyzed by factor analysis. Moreover, the content validity coefficient was calculated as 0.9. This value confirmed acceptable content validity of the questionnaire. To study construct validity, the data obtained form 70 married women with obsessive-compulsive symptoms and their husbands (140 participants) were analyzed via exploratory factor analysis. According to the given form, factor analysis was conducted. Findings of the data analysis indicated that the factor of interactional damages of women with OCPD in their marital relationships was put in the six factor of the questionnaire.

The first factor is radical perfectionism. Perfectionism is a personality trait identified with efforts to be perfect, with high standards, and performances with over-critical evaluation (31). The existence of this factor in obsessive personality is consistent with the research done by (32). Radical perfectionism results in creation of high expectancies of oneself and spouses. As a result, it reduces satisfaction in marital relationships and damages them. These results are consistent with those of $(16,33)$. The second factor was radical anxiety affecting individuals' relationships with 
Table 5. Correlation Matrix of Factors of the Questionnaire

\begin{tabular}{|c|c|c|c|c|c|c|}
\hline \multirow[t]{2}{*}{ Research Variables } & \multicolumn{6}{|c|}{ Factor } \\
\hline & 1 & 2 & 3 & 4 & 5 & 6 \\
\hline Radical perfectionism & 1 & & & & & \\
\hline Radical anxiety & 0.33 & 1 & & & & \\
\hline Coercive and focused control & 0.66 & 0.41 & 1 & & & \\
\hline Frigidity and lack of sexual enjoyment & 0.21 & 0.63 & 0.18 & 0.33 & 1 & \\
\hline Inflexibility & 0.25 & 0.14 & 0.37 & 0.32 & 0.23 & 1 \\
\hline
\end{tabular}

spouses, children, and other individuals. This factor is consistent with the research of (34). Radical anxiety of women with OCPD results in their inconvenience in them and negatively influences their different aspects of lives and martial relationships. The third factor is coercive and focused (non-participatory) control. The existence of this factor in women with OCPD causes damages in their marital relationships. This factor is consistent with the research of (35). Women with OCPD are very controlling and tend to control different dimensions of their husbands' lives. A management system in a coercive, focused, and top-down form shapes the home environment and no authority is given to husbands. In fact, there is a superordinate-subordinate relationship in such an environment. As a result, a kind of sense of captivity appears in husbands and negatively influences marital relationships.

The fourth factor is radical sensitivity to affairs. OCPD creates a lot of sensitivity in interpersonal relationships and results in damages in those relationships in that it devastates interpersonal motivations. This factor and its negative influences in marital relationships are consistent with (36). The fifth factor is frigidity and the lack of sexual enjoyment. Women with OCPD avoid expression of their feelings and emotions. Since their sexual relationships need expression of emotions, OCPD affects negatively their sexual relationships. This factor is consistent with the results of $(10,37)$.

The sixth factor is inflexibility. The main OCPD trait are strict and inflexible behaviors. Those behaviors damage individuals because they prevents their compatibility with life requirements (8). Flexibility needs to accept personal differences and relationships with others particularly intimate relationships. As a result, inflexibility of women's OCPD results in reduction in satisfaction and quality of martial relationships. Researchers found out that individuals with OCPD have an intrinsic tendency to classify and structure their affairs. This issue causes strictness, perfectionism, and stubbornness in them. For example, if a per- son with OCPD faces an unexpected situation, he or she may feel frustration, irritability, and even anger; therefore findings of the present study show that there is a significant correlation between OCPD and aggressiveness in relationships $(29,35)$. In addition, this factor damages intimate relationships. As a result, this finding is consistent with (38).

Generally speaking, the mentioned symptoms and their damages imposed on relations, particularly marital relationships, are consistent with the results $(10,11,39-41)$. The results of the present study also indicated that women with OCPD are unable to make appropriate relationships with acceptable quality and their marital relationships are with damages. Furthermore, the results showed that the development of an instrument for identifying interactional damages of women with OCPD is possible. In addition, the results illustrated that conducing this instrument with an appropriate sample size and doing factor analysis can identify six factors of interactional damages including Radical perfectionism, Radical anxiety, Coercive and focused (non-participatory) control, Radical sensitivity to affairs, Frigidity and lack of sexual enjoyment, Inflexibility. These factors damages relationships of women with OCPD, particularly their marital relationships and provide grounds for providing marital conflicts. Thus to solve their marital problems, these factors should be evaluated and then interventions should be investigated. Questions of the researcher-made question is not only based on reviewing resources, but also interviews with women with OCPD and their husbands as well as experts of OCPD. Therefore, this questionnaire is totally based on Iranian culture and society. Therefore, it enjoys more advantages than nonnative tests and scales.

In the questionnaire developed by the present study, scales were designed in such a way that in addition to identifying the degree of interactional damages of women with OCPD, it can determine damaging domains. In addition, it can explain psychological and behavioral domains 
of women with OCPD. This instrument is a self-reporting questionnaire which can explain evaluation of damages from the viewpoints of women with OCPD. Although it is better to complete this scale with scales of interviewing, observation, and biography of their relatives, specially their husbands, in cases when the sample size is big, it has the highest applicability. As a result, this questionnaire has both clinical and research uses. In addition, according to the questionnaire and the extracted factors, the obsessivecompulsive personality characteristics evaluation form for premarital counseling can be obtained via some modifications. Of limitations of the study, one can refer to the dependency of the results to couples' conditions including the place, husbands' traits, their family lifecycle, etc.). Another limitation can be no investigation of aspects of couples' life (career, education, etc.) are with these characteristics. These limitations are among features and capabilities of qualitative research which make it unique. Thus it is recommended that these limitations be considered in further research.

\section{Acknowledgments}

The researchers sincerely thank all who participated in the interviews and shared their own life affairs.

\section{References}

1. Rosen-Grandon JR, Myers JE, Hattie JA. The Relationship Between Marital Characteristics, Marital Interaction Processes, and Marital Satisfaction. J Counsel Dev. 2004;82(1):58-68. doi: 10.1002/j.15566678.2004.tb00286.x.

2. Gottman JM. What predicts divorce?: The relationship between marital processes and marital outcomes. Psychology Press; 2014.

3. Curran M, Ogolsky B, Hazen N, Bosch L. Understanding marital conflict 7 years later from prenatal representations of marriage. Fam Process. 2011;50(2):221-34. doi: 10.1111/j.1545-5300.2011.01356.x. [PubMed: 21564062].

4. Dildar S, Sitwat A, Yasin S. Intimate enemies: Marital conflicts and conflict resolution styles in dissatisfied married couples. Middle East J Sci Res. 2013;15(10):1433-9.

5. Henry RG, Miller RB. Marital Problems Occurring in Midlife: Implications for Couples Therapists. Am J Fam Ther. 2004;32(5):405-17. doi: $10.1080 / 01926180490455204$.

6. Sappington J, Reedy S, Welch R, Hamilton J. Validity of messages from quadriplegic persons with cerebral palsy. Am J Ment Retard. 1989;94(1):49-52. [PubMed: 2526648].

7. Orth U. How large are actor and partner effects of personality on relationship satisfaction? The importance of controlling for shared method variance. Pers Soc Psychol Bull. 2013;39(10):1359-72. doi: 10.1177/0146167213492429. [PubMed: 23798373].

8. American Psychiatric Association. Diagnostic and statistical manual of mental disorders (DSM-5®). American Psychiatric Pub; 2013.

9. Lewis-Smith J. An examination of the common and unique processes associated with early symptom change as a function of cognitive therapy for avoidant and obsessive-compulsive personality disorders. 2007.

10. South SC, Turkheimer E, Oltmanns TF. Personality disorder symptoms and marital functioning.JConsult Clin Psychol.2008;76(5):769-80. doi: 10.1037/a0013346. [PubMed: 18837594].
11. Cain NM, Ansell EB, Simpson HB, Pinto A. Interpersonal functioning in obsessive-compulsive personality disorder. $J$ Pers Assess. 2015;97(1):90-9. doi: 10.1080/00223891.2014.934376. [PubMed 25046040].

12. Wetterneck CT, Little TE, Chasson GS, Smith AH, Hart JM, Stanley MA. Obsessive-compulsive personality traits: how are they related to OCD severity? J Anxiety Disord. 2011;25(8):1024-31. doi 10.1016/j.janxdis.2011.06.011. [PubMed: 21798711].

13. Fossati A, Beauchaine TP, Grazioli F, Borroni S, Carretta I, De Vecchi C. Confirmatory factor analyses of DSM-IV Cluster C personality disorder criteria. J Pers Disord. 2006;20(2):186-203. doi: 10.1521/pedi.2006.20.2.186. [PubMed: 16643123].

14. Hummelen B, Wilberg T, Pedersen G, Karterud S. The quality of the DSM-IV obsessive-compulsive personality disorder construct as a prototype category. J Nerv Ment Dis. 2008,196(6):446-55. doi: 10.1097/NMD.ob013e3181775a4e. [PubMed: 18552621].

15. Halford WK. Brief therapy for couples: Helping partners help themselves Guilford press; 2003.

16. Hashemi Mofrad S, Jazeeri RS, Fatehizadeh M, Etemadi AS, Abedi MR Detection of pain injuries in women with obsessive-compulsive personality disorder: a qualitative study. Res Behav Sci. 2016;14(3):383-92.

17. Karami M, Haghighi B, Soltanian A, Khosravi A. Potentially Preventable Number of Cases and Deaths Associated with Pneumococcal Diseases and Haemophilus Influenzae in Iran during (2010-2013). Int J Pediatr. 2017;5(2):4395-405.

18. Richter MA, Summerfeldt LJ, Joffe RT, Swinson RP. The Tridimensional Personality Questionnaire in obsessive-compulsive disorder. Psychiatr Res. 1996;65(3):185-8. doi:10.1016/s0165-1781(96)02944-7.

19. Montazeri M. The Effect of schema therapy on the symptoms of obsessivecompulsive personality disorder: A single case study. Faculty of Educational Sciences. University of Esfahan; 2012

20. Mohammadpour A. Anti-methodology: Logic and qualitative knowledge design. Tehran: Publications of Sociologists; 2010.

21. Strauss A, Corbin JM. Basics of qualitative research: Grounded theory procedures and techniques. Sage Publications, Inc;1990.

22. Creswell JW, Creswell JD. Research design: Qualitative, quantitative, and mixed methods approaches. Sage publications; 2017

23. Nilfrooshan P, Ahmadi SA, Fatehizadeh M, Abedi M, Ghasemi R. The structural equation model of the marital relationship quality based on the psychological characteristics of the spouses. Faculty of Education and Psychology. University of Esfahan; 2010.

24. Olia N. The impact of enriching marital life education on couples intimacy. J Fam Res. 2006;6:119-35.

25. Bazargan AS. Introduction to qualitative and mixed research methods. Tehran: Visayat Publishing; 2010.

26. Elo S, Kyngas $\mathrm{H}$. The qualitative content analysis process. J Adv Nurs. 2008;62(1):107-15. doi: 10.1111/j.1365-2648.2007.04569.x. [PubMed: 18352969].

27. Krippendorff K, Bock MA. The content analysis reader. Sage; 2009.

28. Sandelowski M. Whatever happened to qualitative description? Res Nurs Health. 2000;23(4):334-40. doi: 10.1002/1098240x(200008)23:4lt;334::aid-nur9gt;3.0.co;2-g.

29. Cain NM. Interpersonal problem profile of the Pathological Obsessive-Compulsive Personality Scale (POPS). Annual meeting of The Society for Personality Assessment. Boston, MA. 2011.

30. Hashemi Mofrad S, Jazeeri RS, Fatehizadeh M, Etemadi AS, Abedi MR. Investigating the interpersonal interpersonal harm of women with obsessive-compulsive personality symptoms and comparing the effect of individual and paired counseling on the interpersonal harm of a couple and their marital quality. Family counseling. Faculty of Education and Psychology. University of Esfahan; 2017.

31. Yang H, Stoeber J, Wang Y. Moral perfectionism and moral values, virtues, and judgments: A preliminary investigation. Pers Individ Differ. 2015;75:229-33. doi: 10.1016/j.paid.2014.11.040. 
32. Dunkley DM, Blankstein KR, Halsall J, Williams M, Winkworth G. The relation between perfectionism and distress: Hassles, coping, and perceived social support as mediators and moderators. J Counsel Psychol. 2000;47(4):437.

33. Hajloo N, Sobhi-Garamaleki N, Baqeri S. The relationship of perfectionism, self-efficacy, conscientiousness and stress with procrastination. Int J Behav Sci. 2012;6(4):307-14.

34. Hirschfeld RM. Personality disorders: Definition and diagnosis.J Pers Disord. 1993.

35. Villemarette-Pittman NR, Stanford MS, Greve KW, Houston RJ, Mathias CW. Obsessive-compulsive personality disorder and behavioral disinhibition. J Psychol. 2004;138(1):5-22. doi: 10.3200/JRLP.138.1.5-22. [PubMed: 15098711].

36. Henderson L, Horowitz LM. Social allergens and frustrated interpersonal motives. Annual meeting of the Society for Interpersonal Theory and Research. Philadelphia. 2006.

37. Decuyper M, Gistelinck F, Vergauwe J, Pancorbo G, De Fruyt F. Per- sonality pathology and relationship satisfaction in dating and married couples. Personal Disord.2018;9(1):81-92. doi:10.1037/per0000219. [PubMed: 27775412].

38. Stroud CB, Durbin CE, Saigal SD, Knobloch-Fedders LM. Normal and abnormal personality traits are associated with marital satisfaction for both men and women: An Actor-Partner Interdependence Model analysis. J Res Pers. 2010;44(4):466-77. doi: 10.1016/j.jrp.2010.05.011.

39. Bouchard G, Lussier Y, Sabourin S. Personality and Marital Adjustment: Utility of the Five-Factor Model of Personality. J Marriage Fam. 1999;61(3):651. doi: $10.2307 / 353567$.

40. Caughlin JP, Huston TL, Houts RM. How does personality matter in marriage? An examination of trait anxiety, interpersonal negativity, and marital satisfaction. J Pers Soc Psychol. 2000;78(2):326-36. [PubMed: 10707338].

41. Donnellan MB, Conger RD, Bryant CM. The Big Five and enduring marriages. J Res Pers. 2004;38(5):481-504. doi: 10.1016/j.jrp.2004.01.001. 